\title{
Identity Processes, Depression, and the Aging Self-A Norwegian Study
}

\author{
Gail Low ${ }^{1}$, Mary Kalfoss' ${ }^{2}$, Liv Halvorsrud ${ }^{3}$ \\ ${ }^{1}$ University of Alberta, Edmonton, Canada \\ ${ }^{2}$ Diakonova University College, Oslo, Norway \\ ${ }^{3}$ Oslo and Akershus University, College of Applied Sciences, Oslo, Norway \\ Email: gail.low@ualberta.ca
}

Received 3 October 2015; accepted 11 November 2015; published 17 November 2015

Copyright (C) 2015 by authors and Scientific Research Publishing Inc.

This work is licensed under the Creative Commons Attribution International License (CC BY). http://creativecommons.org/licenses/by/4.0/

(c) (i) Open Access

\section{Abstract}

The Identity Process Theory is a theory of how people adapt to aging. According to this theory, older people attribute their physical functioning to a more variable state of health or to their age. Health attributions per se help older people avoid negative thoughts and feelings about themselves and their own process of aging. We explored health versus age attributions, and their effects upon depressive symptoms and negativity toward aging among 359 older Norwegians (age range $=60$ - 91 years of age). Aging pertained to psychosocial loss, physical change, and psychological growth. Data collected in the 2004 WHOQOL-OLD Norwegian Field Study were analyzed by using a MANOVA and a validatory path analysis. Our findings consistently supported health attributions in relation to psychosocial loss $\left(X^{2}=20.37, \mathrm{df}=10, \mathrm{p}=0.03\right.$; GFI $=0.98, \mathrm{AGFI}=0.95$, RMSEA $=0.05)$, physical change $\left(X^{2}=35.03, \mathrm{df}=14, \mathrm{p}=0.000 ; \mathrm{GFI}=0.97\right.$, AGFI $=0.94$, RMSEA $=$ 0.06), and psychological growth $\left(X^{2}=22.22\right.$, df $=13, \mathrm{p}=0.05$; GFI $=0.98$, AGFI $=0.96$, RMSEA $=$ 0.04). Health attributions increased participants' depressive symptoms and negativity toward aging, especially toward psychosocial loss $(\beta=-0.45, \mathrm{p}=0.000)$ and physical change $(\beta=-0.48, p=$ $0.000)$. We relate these theoretically contradictory findings to Norwegian cultural beliefs and values. We make recommendations for research, including normalizing depressive symptoms and crosscultural investigations.

\section{Keywords}

Aging, Identity, Depression, Norway, MANOVA, AMOS

\section{Introduction}

The average life expectancy in Norway is 81.4 years of age [1] and will increase to 85 by 2025 [2]. Those 65 
and older make up $14.7 \%$ of the population and will increase to $18 \%$ in 2020 and $24 \%$ in 2050 [3]. Understanding how older adults adapt to their own aging is increasingly important given these predictions. Very little is known about how older Norwegians psychologically adapt to their own process of aging. Norwegian women 40 to 80 years of age have reported being more satisfied with their age and less concerned about being considered elderly than Norwegian men [4]. However, older Norwegians have also been found to be far less optimistic than older Canadians about aging physically, and to view older age as a time of psychosocial loss and growth [5]. Otherwise, older Norwegians have deemed important being self-sufficient in managing the physical changes of aging [6]. According to the Identity Process Theory (IPT), physical functioning in terms of the body's ability to perform everyday activities is the most important aspect of identity in older age [7]. To minimize or ideally avoid any negativity towards themselves and their own process of aging, older people deny that their physical functioning has anything to do with age [8]. We investigated whether older Norwegians denied age-related changes in their physical functioning, and whether this made them less prone to symptoms of depression and more positive about aging. We analyzed secondary data collected in the 2004 Norwegian WHOQOL-OLD field study from 359 adults between 60 and 91 years of age.

The IPT is a theory of how people adapt to aging. According to the IPT, the physical sense of self or physical identity has three attributes: physical appearance, the body's ability to perform everyday activities, and mortality risk [8]. We focus on physical functioning in terms of performing everyday activities. This bodily ability is the most important aspect of older peoples' physical identity [7]. In older age, people tend to expect and be the most vigilant about losses in independence [7] [8].

Acknowledging losses in physical functioning is psychologically painful [9] [10]. This makes older people prone to negative thoughts and feelings about themselves and their own process of aging [7] [11]. People tend to interpret painful losses in a way that helps them maintain a positive sense of identity [8]. Older people use the identity assimilation process to maintain a youthful physical identity [7] [8] [11]. In other words, older people attribute their physical functioning to a more variable state of health. Any difficulties they encounter in physical functioning have nothing to do with age. Health can wax and wane. Aging is irreversible and unidirectional.

Identity accommodation is the process of attributing physical functioning to age [8]. People who make agerelated attributions dwell upon functional difficulties [11]. Even the slightest difficulties are interpreted as a sign that total physical dependence is close at hand [7]. Identity accommodators are full of self-doubt and prone to negative thoughts and feelings about themselves and their own process of aging [7] [11]. The identity accommodation process is used only when everyday activities become unmanageable [7] [8].

Ideally, older people use assimilation and accommodation identity processes to achieve identity balance [8]. Having identity balance means acknowledging age-related difficulties with physical functioning without dwelling upon them [11]. This helps to minimize older peoples' negativity about themselves and aging [7].

The IPT has been predominantly tested among American adults in their 40s to their 80s. Use of the identity assimilation process, as opposed to identity accommodation, has tended to increase with age [7]-[11]. Use of the assimilation process has been positively associated with self-esteem [8] [10]. The accommodation process has provoked low self-esteem [7]-[10], and self-blame and the inability to deny negative experiences in general [7]. Identity accommodators also tend to be more self-reflective and self-conscious than identity assimilators [11]. Identity balance has been associated with healthy internal state awareness [11] and higher self-esteem [7] [9] [10].

Identity processes have been studied mostly in relation to self-esteem or negativity toward the self among adults from midlife onward. Seldom is negative affect looked at. We were particularly interested in depression because approximately $25 \%$ - 35\% of Norwegians aged over 65 years old suffer from mild depression, while $8.4 \%$ are believed to suffer from severe depression [12]. We did find one IPT study on depression reporting that neither identity assimilation nor identity balance reduced older American's symptoms of depression [13]. The authors link this contradictory finding to the questioning of one's own worth and usefulness in a society that values youth over old age. Testing the IPT in relation to culture has been scarce. We found only one additional study. In this study, the assimilation process and its enhancing effect on self-esteem was significantly higher among American versus Dutch adults of all age [14]. The authors wondered whether it was less important to deny one's own aging in the Netherlands wherein youth was not valued over old age.

Norway occupies the highest Nordic ranking for valuing of all citizens' social security, human compassion, and cohesiveness among family and community [15]. This country boasts accessible health and social care, and public pension plans [1]. Excepting physicians, nurses, police and military workers, there is also no retirement age in Norway. Just over one-quarter of Norway's workforce is consistently over 65 years of age [1]. In keeping 
with Norway's Nordic ranking, its citizens are instructed to abide by the Likhet. The Likhet instructs Norwegians that no one ought to be or should be made to feel more deserving or important in the conduct of everyday matters [16]. The Norwegian practice of carefully choosing whom one is socially accessible to confirms an individual's worth and uniqueness [16]. Nonetheless hierarchical relationships are largely unwanted and often met with suspicion [15]. Norwegians' trust in others is highest worldwide [17]. Norwegian society is an egalitarian society frowning upon social hierarchies and self-importance. The explicit emphasis on solidarity and equality is, arguably, discordant with valuing youth over older age. Norwegian society is striving toward a fully participatory society espousing positive attitudes toward older people [18]. These are social principles that all Norwegians ought to live by. Whether older Norwegians themselves would deny or acknowledge aging is not known.

We explored identity process use among Norwegian adults who were 60 years of age and older. We also investigated the psychological effects of those processes in terms of depressive symptoms and aging itself. We asked: 1) Would older Norwegians attribute their physical functioning to a more variable state of health (identity assimilation process), age (identity accommodation process), or both (identity balance process)? 2) What effect would older Norwegians' attribution processes have upon their ability to circumvent depressive symptoms and negativity toward their own process of aging?

\section{Methods}

We conducted a secondary analysis of data collected in 2004 as part of a larger field study of quality of life of older adults funded by the European Commission conducted in collaboration with the World Health Organization [19]. Data were collected relating to qualities of life, self-reported health, attitudes toward aging, and demographic characteristics (i.e. gender, age, marital status, education).

\subsection{Participants \& Sampling}

Two cohorts took part in the Norwegian Field Study. The largest consisted of a randomly selected stratified sample of older adults from 20 dispersed communities drawn by allocated proportional design by Statistics Norway. The second cohort consisted of those who were unusually frail and living in institutional settings. Inclusion criteria were: 60 or more years of age, Norwegian speaking, resident of Norway, no illness likely to cause death within the next six months, and no significant cognitive impairment. Of the 802 older adults invited to participate, 401 returned questionnaires by mail.

\subsection{Measurements}

1) The Aging Process. Participants' perceptions of their own aging process were measured using the Attitudes to Ageing Questionnaire or AAQ [20]. The AAQ consists of 24 items relating to three domains: psychosocial loss, physical change; and psychological growth. Psychosocial loss is about whether respondents equate old age with them being lonely, depressed, and having loss, whether they are currently feeling disengaged from society and excluded from things, and as they get older, are losing their physical independence, and having difficulty making friends and talking about their feelings. Respondents are also asked about physical changes (their aging ease, feeling old, identity not being defined by age, energy and health at present given their age, physical health problems not holding them back, and exercise regularity and importance). The psychological growth that comes with aging is about better coping and self-acceptance, believing one's life has made a difference, seeing aging as a privilege and as pleasant, giving of and being a good example to others, and felt wisdom. All of these self-report ratings range from 1 to 5 ; 1 reflects strongly disagree or not at all true, and 5 reflects strongly agree or extremely true.

The validity and reliability of the AAQ has been established using both classical and modern psychometric methods, and pooled data from 20 countries [20]. Internal consistencies for this study sample were: psychosocial loss $\alpha=0.73$, physical change $\alpha=0.75$, and $\alpha=0.73$ for psychological growth.

2) General Health. Participants' general health was assessed using the General Health item of the SF-12 Version 1 [21]. This item asks: In general, would you say your health is excellent, very good, fair, or poor? In the 5-item General Health scale, respondents are first asked to rate their health. This item was recorded so that its 5-point Likert scale response categories ranged from "poor" to "excellent”. Because this subdomain asks for two-week ratings, scores are implicitly more variable than age. 
3) Physical Functioning. Participants’ physical functioning was measured using the two-item Physical Functioning subdomain of the SF-12 [21]. This domain focuses on everyday activity performance. Item 1 asks: How does your health now limit you in moderate activities, such as moving a table, pushing a vacuum cleaner, bowling, or playing golf? Item 2 asks: How about climbing several flights of stairs? Would you say your health limited you a lot, a little, or not at all? The 3-point Likert scale response categories for both items are: "Yes, limited a lot", "Yes, somewhat limited", and "No, not limited at all".

General Health and Physical Functioning scores were standardized on a common metric by using linear z-transformation subdomain equations [21]. Each subdomain is scored to have a standard deviation of 10 and a mean of 50. Individuals who score below 45 are considered below the average range of scores for each SF-12 subdomain in the US general population. Individual norming of subdomains permits researchers to use them separately.

4) Depressive Symptoms. Depressive symptoms were measured using the short-form Geriatric Depression Scale [22]. All 15 items are scored dichotomously (No/Yes) and to obtain a depression score, the number of depressive symptoms is totalled. The value range is 0 to 15 , with higher values indicating more depressive symptoms; the time frame for the measure is the present. Scores from 5 - 8 indicate mild depression; scores from 9 11 indicate moderate depression; and scores from 12 - 15 indicate severe depression. The consistency reliability of the GDS-15 was $\alpha=0.80$.

5) Covariates.Gender was treated as a covariate [4] [7] [9] [11]. So too were the dummy variables of education and living arrangements. Family traditions and connections are a core element of older Norwegians' social identity [15] [23]. Approximately one-third of our participants were receiving help with day-to-day activities from adult children and partners (Table 1). Over one-third (38.4\%) of our participants also had various forms of post-secondary education, including college and university. Education has been linked with Norwegians' propensities to remain actively engaged in some form of work in their communities [24].

\subsection{Data Analysis}

We had complete data for analysis on 382 Norwegian Field Study participants. We excluded 15 unusually frail participants who were no longer able to live in their own homes. Eight others had not reported their gender. Our final sample size was $\mathrm{n}=359$.

1) GLM Regression. The study data were analysed through a regression analysis using the GLM procedure within SPSS [25]. Beta coefficients are estimates of the increase or decrease in dependent variable scores for every 1 point increase in interval level independent variable scores. For dummy variables, dependent variable group means are contrasted against reference category (coded as "1") group means. In our case, then, the beta coefficient for gender equals the "mean dependent variable score for women" minus the "mean score for men on that dependent variable". GLM regressions provide estimates of the statistical power to detect significant effects. Marginal dependent variable means that are adjusted for all other variables in one's model can be estimated for categorical variables. In the first GLM regression, AAQ physical change, psychosocial loss, psychological growth scores were simultaneously dependent variables. Correlations between physical change, and psychological growth and psychosocial loss domains were $r=0.529(p=0.000)$ and $r=0.242(p=0.000)$, respectively. Modelling in simultaneity ensures that regression coefficients for independent variables are not inflated and tailored to each AAQ score [25].

Testing the IPT required interaction effects. The identity assimilation (attributing one's physical functioning to one's health in general) interaction effect was physical function * general health. The identity accommodation (attributing physical functioning to one's age) interaction effect was physical function * age. We centred all interaction terms [25]. Marginal means for AAQ scores were estimated for our three dummy covariates. In the second GLM regression, GDS scores were the dependent variable. AAQ scores were treated as covariates. Marginal GDS mean scores were estimated for our three dummy covariates.

2) AMOS. GLM regressions yield more parsimonious models for validation testing in path analysis [25]. We validated all statistically significant predictors of each AAQ domain score and GDS scores using AMOS V23.0. The goodness-of-fit of these GLM-derived relationships was assessed using the Model Chi-square statistic $\left(X^{2}\right)$, Goodness-of-Fit Index (GFI), Adjusted Goodness of Fit (AGFI), and Root Mean Square Error of Approximation or RMSEA [26]. The ideal p-value for model $X^{2}$ is 0.05 or greater. This would indicate that a path model has a near perfect fit with one's real-world data. Model-implied relationships fit real-world data approximately and 
never exactly; this is more realistic [26]. The GFI is the percentage of 'match' between model-implied relationships and the sample data; ideally, this match is 95\%. The AGFI imposes a GFI penalty for the inclusion of additional parameters. The RMSEA is an estimate of error between how well model-implied relationships approximate the sample data. Reasonable estimates for the RMSEA are 0.05 - 0.08 [26].

\section{Results}

The characteristics of our 359 participants, along with a statistical description of their SF-12, AAQ and GDS scores are shown in Table 1. General health scores were roughly 1/2 of a standard deviation below the expected norm of 45. Physical functioning scores hovered around this norm. Approximately $12 \%$ of our participants had mild depression; 3.3\% had moderate to severe depression. Participants were most positive about psychosocial loss and most pessimistic about physical changes in terms of their own process of aging.

GLM Regression Step 1 (AAQ scores). Statistically significant main effects on AAQ scores were observed for age $(\mathrm{F}=10.09, \mathrm{df}=3, \mathrm{p}=0.000$; power $=0.998)$, physical function $(\mathrm{F}=10.82, \mathrm{df}=3, \mathrm{p}=0.000$; power $=$ 0.999), general health $(F=82.73, d f=3, p=0.000$; power $=1.00)$, and GDS scores $(F=24.27, d f=3, p=0.000$; power $=1.00)$. There were no significant main effects for physical function * general health $(\mathrm{F}=0.642, \mathrm{df}=3, \mathrm{p}$ $=0.589)$ or physical function * age $(\mathrm{F}=1.732, \mathrm{df}=3, \mathrm{p}=0.160)$. Gender $(\mathrm{F}=4.92, \mathrm{df}=3, \mathrm{p}=0.002$; power $=$ 0.909), education $(\mathrm{F}=5.07, \mathrm{df}=3, \mathrm{p}=0.002$; power $=0.918)$, and living arrangements $(\mathrm{F}=3.29, \mathrm{df}=3, \mathrm{p}=0.021$; power $=0.750$ ) had significant main effects on AAQ scores. Table 2 shows domain-specific patterns of statistically significant main effects. Age, gender, general health, living arrangements, and GDS scores had main

Table 1. Participant characteristics $(n=359)$.

\begin{tabular}{|c|c|c|c|}
\hline Sociodemographics & Number & Percent & Mean (SD), Range \\
\hline Female gender & 197 & $54.9 \%$ & \\
\hline Less than post-secondary & 221 & $61.6 \%$ & \\
\hline Post-secondary & 138 & $38.4 \%$ & \\
\hline Living unsupported & 252 & $70.2 \%$ & \\
\hline Living with family support & 107 & $29.8 \%$ & \\
\hline Married/with partner & 321 & $90.4 \%$ & \\
\hline Unmarried & 34 & $9.6 \%$ & \\
\hline Unhealthy & 52 & $14.5 \%$ & \\
\hline Healthy & 299 & $83.3 \%$ & \\
\hline Age & & & 74.78 (7.99), 60 - 91 \\
\hline Comorbidities & & & 1 (0.97), 0 - 5 \\
\hline \multicolumn{4}{|l|}{ SF-12 } \\
\hline General Health & & & 40.31 (11.45), 18.87 - 61.99 \\
\hline Physical Function & & & 44.74 (11.92), 22.11 - 56.47 \\
\hline GDS-SF ${ }^{\mathrm{a}}$ & & & 2.30 (2.53), 0 - 14 \\
\hline $0-4$ & 283 & $84.8 \%$ & \\
\hline 5 - 8 (Mild depression) & 34 & $11.9 \%$ & \\
\hline 9 - 11 (Moderate depression) & 9 & $2.7 \%$ & \\
\hline 12 - 15 (Severe depression) & 2 & $0.6 \%$ & \\
\hline \multicolumn{4}{|l|}{$\mathrm{AAQ}^{\mathrm{b}}$} \\
\hline Physical Change & & & 26.75 (5.64), $10-40$ \\
\hline Psychosocial Loss & & & 29.98 (4.94), 13 - 40 \\
\hline Psychological Growth & & & 28.62 (4.59), 15 - 40 \\
\hline
\end{tabular}

a. GDS-SF: Geriatric Depression Scale Short-form; b. AAQ: Attitudes to Aging Questionnaire. 
Table 2. GLM Regression (MANOVA) for self-perceptions of aging $(\mathrm{n}=359)$.

\begin{tabular}{|c|c|c|c|c|}
\hline & $\begin{array}{l}\text { Univariate } \\
\text { Effects F, df }\end{array}$ & $\begin{array}{l}\text { B Coefficient } \\
\text { (Standard Error) }\end{array}$ & Power & $\begin{array}{l}\text { Estimated Marginal Means Test }{ }^{\mathrm{a}} \\
\text { Adjusted Mean (Standard Error) }^{\mathrm{b}}\end{array}$ \\
\hline Psychosocial Loss & & & & Grand Mean = $30.38(0.33)$ \\
\hline Age & $26.57,1^{* * *}$ & $-0.13(0.03)^{* * *}$ & 0.983 & \\
\hline Gender $(M=1)^{c}$ & $7.73,1^{* *}$ & $1.13(0.48)^{* *}$ & 0.650 & $\mathrm{~F}=30.50(0.38) ; \mathrm{M}=29.37(0.42)^{*}$ \\
\hline Education $(\mathrm{PS}=1)^{\mathrm{d}}$ & $1.25,1 \mathrm{a}$ & $0.21(0.49) \mathrm{a}$ & 0.073 & $<\mathrm{PS}=30.05(0.36) ; \mathrm{PS}=29.84(0.43) \mathrm{a}$ \\
\hline General Health & $42.33,1^{* * *}$ & $0.06(0.03)^{* * *}$ & 0.598 & \\
\hline Physical Function & $0.113,1 \mathrm{a}$ & $-0.02(0.03) \mathrm{a}$ & 0.094 & \\
\hline Living Arrangements $(\mathrm{LS}=1)^{\mathrm{e}}$ & $8.05,1^{* *}$ & $-10.34(0.54)^{* *}$ & 0.692 & LU = 29.27 (0.32); LS = $30.61(0.49)^{*}$ \\
\hline Physical Function * General Health & $1.197,1 \mathrm{a}$ & $0.001(0.002) \mathrm{a}$ & 0.206 & \\
\hline Physical Function * Age & $1.04,1 \mathrm{a}$ & $-0.002(0.002) a$ & 0.174 & \\
\hline Depression & $51.99,1^{* * *}$ & $-0.84(0.11)^{* * *}$ & 1.00 & \\
\hline \multicolumn{5}{|l|}{ Adjusted R-squared $=0.268$} \\
\hline Physical Change & & & & Grand Mean = $26.79(0.33)$ \\
\hline Age & $2.31,1 \mathrm{a}$ & 0.03(0.03)a & 0.162 & \\
\hline Gender & $2.24,1 \mathrm{a}$ & $0.17(0.50) a$ & 0.063 & $\mathrm{~F}=26.62(0.41) ; \mathrm{M}=26.45(0.42) \mathrm{a}$ \\
\hline Education & $2.76,1 \mathrm{a}$ & $0.28(0.52) \mathrm{a}$ & 0.083 & $<\mathrm{PS}=26.68(0.38) ; \mathrm{PS}=26.40(0.46) \mathrm{a}$ \\
\hline General Health & $176.06,1^{* * *}$ & $0.16(0.03)^{* * *}$ & 1.00 & \\
\hline Physical Function & $22.31,1^{* * *}$ & $0.10(0.03)^{* * *}$ & 0.905 & \\
\hline Living Arrangements & $1.30,1 \mathrm{a}$ & $0.64(0.57) \mathrm{a}$ & 0.202 & $\mathrm{LU}=26.86(0.34) ; \mathrm{LS}=26.22(0.51) \mathrm{a}$ \\
\hline Physical Function * General Health & $0.755,1 \mathrm{a}$ & $0.002(0.002) \mathrm{a}$ & 0.124 & \\
\hline Physical Function * Age & $1.04,1 \mathrm{a}$ & $0.004(0.003) \mathrm{a}$ & 0.376 & \\
\hline Depression & $16.55,1^{* * *}$ & $-0.49(0.12)^{* * *}$ & 0.979 & \\
\hline \multicolumn{5}{|l|}{ Adjusted R-squared = 0.378} \\
\hline Psychological Growth & & & & Grand Mean = $28.53(0.33)$ \\
\hline Age & $0.004,1 \mathrm{a}$ & $0.002(0.03) \mathrm{a}$ & 0.050 & \\
\hline Gender & $1.96,1 \mathrm{a}$ & $0.16(0.51) \mathrm{a}$ & 0.062 & $\mathrm{~F}=28.61(0.40) ; \mathrm{M}=28.61(0.42) \mathrm{a}$ \\
\hline Education & $5.93,1^{*}$ & $1.25(0.51)^{*}$ & 0.681 & $<\mathrm{PS}=29.15(0.38) ; \mathrm{PS}=27.90(0.46)^{*}$ \\
\hline General Health & $0.53,1 \mathrm{a}$ & $0.02(0.03) \mathrm{a}$ & 0.112 & \\
\hline Physical Function & $1.30,1 \mathrm{a}$ & $-0.03(0.03) \mathrm{a}$ & 0.207 & \\
\hline Living Arrangements & $0.018,1 \mathrm{a}$ & $-0.08(0.57) \mathrm{a}$ & 0.052 & $\mathrm{LU}=28.49(0.34) ; \mathrm{LS}=28.57(0.51) \mathrm{a}$ \\
\hline Physical Function * General Health & $0.074,1 \mathrm{a}$ & $0.001(0.002) \mathrm{a}$ & 0.062 & \\
\hline Physical Function * Age & $3.26,1 \mathrm{a}$ & $0.004(0.002) \mathrm{a}$ & 0.437 & \\
\hline Depression & $20.57,1^{* * *}$ & $-0.55(0.12)^{* * *}$ & 0.995 & \\
\hline Adjusted R-squared $=0.078$ & & & & \\
\hline
\end{tabular}

${ }^{\mathrm{a}}$ Scheffe's test used for means comparisons when equal variances assumed; when unequal variances not assumed; Game-Howell used; ${ }^{\mathrm{b}}$ All marginal means are adjusted for all other covariates; ${ }^{c} \mathrm{~F}=$ female $(\mathrm{n}=192), \mathrm{M}=$ male $(\mathrm{n}=155) ;{ }^{\mathrm{d}} \mathrm{PS}=$ no post-secondary education $(\mathrm{n}=209)$, PS = post-secondary education $(\mathrm{n}=138) ;{ }^{\mathrm{e}} \mathrm{LU}=$ living unsupported $(\mathrm{n}=252)$, $\mathrm{LS}=$ living supported $(\mathrm{n}=107)$; $\mathrm{a}=$ not statistically significant, ${ }^{*} \mathrm{p}<0.05$, ${ }^{* *} \mathrm{p}<0.01,{ }^{* * *} \mathrm{p}<0.001$.

effects upon psychosocial loss scores. General health, physical function, and GDS scores had main effects upon physical change scores. GDS scores affected psychological growth scores. Marginal mean estimates for psychosocial loss were significantly higher among women and those living with family support. Participants with post-secondary education had significantly lower psychological growth scores.

GLM Regression Step 2 (GDS scores). Age, general health, and physical functioning had statistically significant main effects on GDS scores (Table 3). Physical functioning * general health significantly predicted GDS scores. For every one point increment in physical functioning or general health scores, GDS scores increased by 0.005. General Health scores ranged from 18.87 - 61.99. Physical Functioning scores ranged from 22.11 - 56.47. 
Table 3. GLM Regression (ANOVA) for depression $(\mathrm{n}=359)$.

\begin{tabular}{|c|c|c|c|c|}
\hline & $\begin{array}{l}\text { Univariate } \\
\text { Effects F, df }\end{array}$ & $\begin{array}{l}\text { B Coefficient } \\
\text { (Standard Error) }\end{array}$ & Power & $\begin{array}{l}\text { Estimated Marginal Means Test } \\
\text { Mean (Standard Error) }\end{array}$ \\
\hline Depression & & & & Grand Mean = 2.29 (2.53) \\
\hline Age & $5.29,1^{*}$ & $0.03(0.01)^{*}$ & 0.631 & \\
\hline Gender $^{c}$ & $3.07,1 \mathrm{a}$ & $0.39(0.22) \mathrm{a}$ & 0.416 & $\mathrm{~F}=1.58(0.18) ; \mathrm{M}=1.96(0.18) \mathrm{a}$ \\
\hline Education $^{\mathrm{d}}$ & $2.30,1 \mathrm{a}$ & $-0.34(0.23) \mathrm{a}$ & 0.327 & $<\mathrm{PS}=1.94(0.16) ; \mathrm{PS}=0.60(0.20) \mathrm{a}$ \\
\hline General Health & $49.41,1 * * *$ & $-0.08(0.01)^{* * *}$ & 1.00 & \\
\hline Physical Function & $8.72,1^{* *}$ & $-0.04(0.01)^{* *}$ & 0.838 & \\
\hline Living Arrangements ${ }^{\mathrm{e}}$ & $0.77,1 \mathrm{a}$ & $-0.22(0.25) \mathrm{a}$ & 0.141 & $\mathrm{LU}=1.88(0.15) ; \mathrm{LS}=1.66(0.22) \mathrm{a}$ \\
\hline Physical Function * General Health & $37.42,1 * * *$ & $0.005(0.001)^{* * *}$ & 1.00 & \\
\hline Physical Function * Age & $1.71,1 \mathrm{a}$ & $-0.001(0.001) \mathrm{a}$ & 0.256 & \\
\hline Adjusted R-squared $=0.399$ & & & & \\
\hline
\end{tabular}

a. Scheffe's test used for means comparisons when equal variances assumed; when unequal variances not assumed; Game-Howell used; b. All marginal means are adjusted for all other covariates; $c$. $F=$ female $(n=192), M=$ male $(n=155)$; d. $P S=$ no post-secondary education $(n=209)$, $P S=$ post-secondary education $(\mathrm{n}=138)$; e. $\mathrm{LU}=$ living unsupported $(\mathrm{n}=252), \mathrm{LS}=$ living supported $(\mathrm{n}=107) ; \mathrm{a}=$ not statistically significant, ${ }^{*} \mathrm{p}<0.05$, ${ }^{* *} \mathrm{p}<0.01,{ }^{* * *} \mathrm{p}<0.001$

Table 4. Model variable correlation matrix $(n=359)$.

\begin{tabular}{ccccccccc}
\hline & Gender & Age & Education & Liv Arr & GH & PF & PF*GH & PF * Age \\
\hline Gender & 1.00 & & & & & & & \\
Age & $0.02 \mathrm{a}$ & 1.00 & & & & & & \\
Education & $0.27^{* *}$ & $-0.16^{* *}$ & 1.00 & & & & & \\
Liv Arr & $-0.11^{* *}$ & $0.26^{* * *}$ & $-0.09 \mathrm{a}$ & 1.00 & & & & \\
$\mathrm{GH}^{\mathrm{b}}$ & $0.09 \mathrm{a}$ & $-0.05 \mathrm{a}$ & $0.17^{* *}$ & $-0.28^{* * *}$ & 1.00 & & & \\
$\mathrm{PF}^{\mathrm{c}}$ & $0.21^{* *}$ & $-0.22^{* * *}$ & $0.18^{* * *}$ & $-0.37^{* * *}$ & $0.64^{* * *}$ & 1.00 & & \\
$\mathrm{PF}^{*} \mathrm{GH}$ & $-0.06 \mathrm{a}$ & $-0.01 \mathrm{a}$ & $0.01 \mathrm{a}$ & $0.12^{*}$ & $-0.14^{* *}$ & $-0.32^{* *}$ & 1.00 & \\
$\mathrm{PF}^{*}$ Age & $0.01 \mathrm{a}$ & $0.00 \mathrm{a}$ & $-0.01 \mathrm{a}$ & $-0.09 \mathrm{a}$ & $-0.01 \mathrm{a}$ & $0.04 \mathrm{a}$ & $0.00 \mathrm{a}$ & 1.00 \\
\hline
\end{tabular}

a. Liv Arr: Living Arrangements; b. GH: General Health; c. PF: Physical Function; a = not statistically significant, ${ }^{*} \mathrm{p}<0.05,{ }^{* *} \mathrm{p}<0.01,{ }^{* * *} \mathrm{p}<$ 0.001

The study variable correlation matrix is shown in Table 4 . We included only the interaction term physical functioning * general health because the correlation between either term approached the collinear criterion of $\mathrm{r}=$ 0.70. GLM beta coefficients are isolated estimates [25]. AMOS estimates are simultaneous estimates [26].

Figure 1, Figure 2, and Figure 3 depict all other statistically significant predictors of AAQ and GDS scores that were identified in both GLM analyses. For clarity purposes, we have left out independent variable correlations that were found not to be statistically significant. The fit indices shown in all three figures are indicative of reasonable goodness-of-fit with our sample data. Except for the $X^{2} \mathrm{p}$-values for psychosocial loss and physical change scores, all other indices indicated goodness-of-fit.

In Figures 1-3, being a woman was significantly associated with not having post-secondary education. Advancing age was associated with living with the support of adult children and/or a partner. Living supported was significantly associated with the interaction term physical functioning * general health. Across all three figures, GDS scores increased with age. Physical functioning * general health had a significant positive effect upon GDS scores. As GDS scores increased, psychosocial loss, physical change, and psychological growth scores significantly declined. We observed effects peculiar to our covariates. Figure 1 shows that men exhibited significantly more negativity toward psychosocial loss than did women. As shown in Figure 3, the post-secondary education significantly enhanced negativity toward psychological growth. Notwithstanding the latter two covariate effects were small in stature.

\section{Discussion}

We explored identity process use among 359 older Norwegians, and how those processes affect depressive 


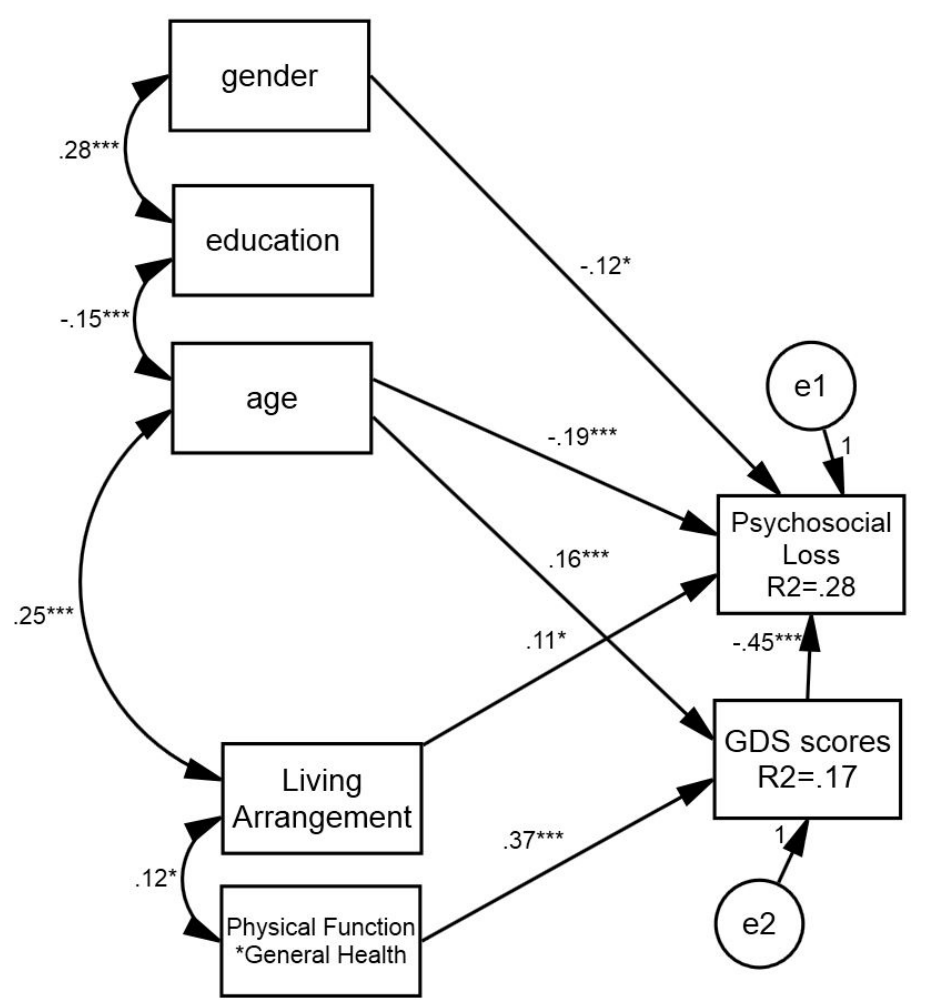

Figure 1. Psychosocial loss model $(\mathrm{n}=359)$. Model $X^{2}=20.37, \mathrm{df}=10, \mathrm{p}=0.03$; GFI $=0.98$, AGFI $=0.95$, RMSEA $=0.05 .{ }^{*} p<0.05,{ }^{* * *} p<0.001$. GDS $=$ Geriatric depression scale.

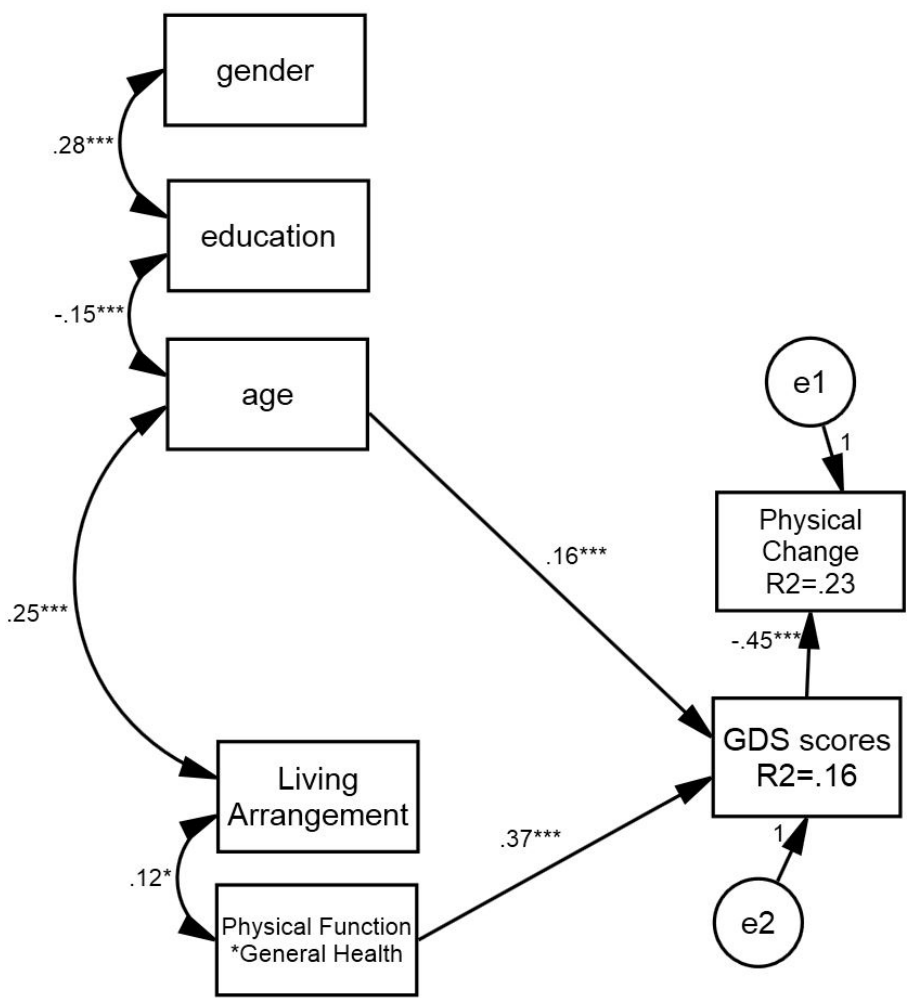

Figure 2. Physical change model $(\mathrm{n}=359)$. Model $X^{2}=35.03, \mathrm{df}=14, \mathrm{p}=0.00$; GFI $=0.97$, AGFI $=0.94$, RMSEA $=0.06 .{ }^{*} \mathrm{p}<0.05,{ }^{* * *} \mathrm{p}<0.001$. GDS $=$ Geriatric depression scale. 


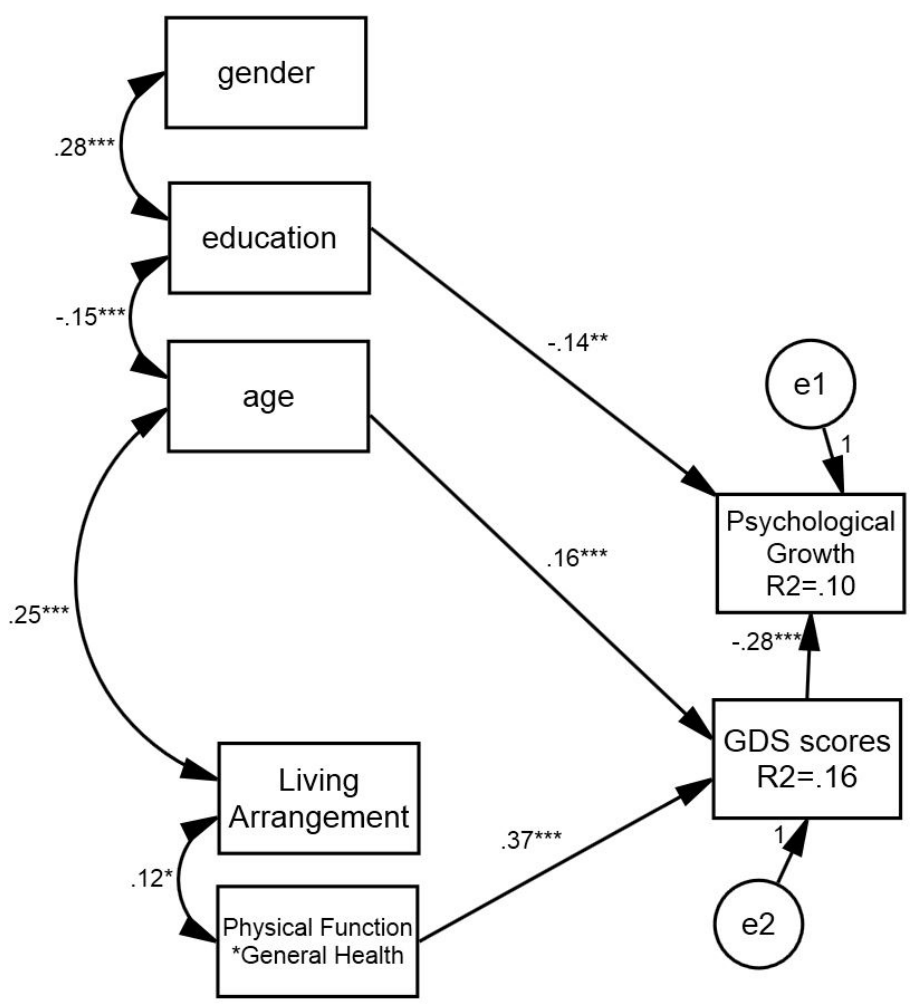

Figure 3. Psychological growth model $(\mathrm{n}=359)$. Model $X^{2}=22.22$, $\mathrm{df}=13, \mathrm{p}=0.05$; $\mathrm{GFI}=$ 0.98 , AGFI $=0.96$, RMSEA $=0.04 ;{ }^{*} \mathrm{p}<0.05,{ }^{* * *} \mathrm{p}<0.001$; GDS $=$ Geriatric depression scale.

symptoms and negativity toward their own process of aging. Our participants attributed physical functioning to their more variable state of health, not their age. In theory, this identity assimilation process circumvents negative thoughts and feelings [7] [11]. In our case, use of identity assimilation enhanced our participants' depressive symptoms and negativity toward aging, particularly toward psychosocial loss and physical change. Use of the assimilation process was also significantly associated with living with the support of adult children and/or a partner.

The identity assimilation process has been found not to reduce older American's symptoms of depression [13]. This theoretical contradiction was attributed to living in a youth-conscious society. In a similar vein, Dutch as opposed to American adults of all ages did not use the identity assimilation process [14]. Both studies emphasize relating findings to cultural beliefs and values. Cultural beliefs and values connote appropriate ways of thinking and doing in relation to the self and to others. Wanting to be accepted within one's own culture and live life according to prescribed cultural beliefs and values is natural for everyone [27].

In Norway appropriate ways of thinking and doing are prescribed in the Likhet [16]. A principle norm is that Norwegians should not dwell on themselves nor see themselves as more deserving or important than others. People who use the identity assimilation process tend not to dwell upon their physical functioning and avoid attributing this aspect of identity to age [7] [8] [11]. Perhaps the older adults living with support considered it culturally appropriate to attribute physical functioning to their more variable state of health? Age-related attributions equate with acknowledging that one's own aging process has irreversibly asserted itself [8]. Family traditions and connections are core elements of Norwegians' social identity [15] [23]. Family have largely contributed to caring for older kin [28]. The propensity for identity assimilation among those living supported could be rooted in the desire to minimize worry among adult children and partners. Family responsibility norms have also been undergoing change [28].

Attributing physical functioning to a more variable state of health or not dwelling upon one's physical circumstances condones a Likhet-based norm. Living without support contradicts an equally revered social norm in Norwegian society. We did find that living supported significantly but weakly enhanced perceptions of psychosocial loss. This psychological benefit paled in comparison to the consequences of identity assimilation. These 
consequences were moderately enhanced depressive symptoms and negativity toward psychosocial loss and psychological growth. The detrimental effect of depressive symptoms was borderline-moderate for psychological growth and moderate for psychosocial loss. Having little social contact with family has enhanced mental distress in older Norwegians [29]. Seemingly, maintaining a more youthful physical identity was psychological costly for participants living with the support of adult children and/or a partner. It meant denying their social identity.

Between 25\% - 30\% of older Norwegians suffer from some form of clinical depression while $8.4 \%$ experience severe depression [12]. Less than $1 \%$ of our participants reported severe depressive symptoms, although $12 \%$ reported mild to moderate depression. There is still a certain degree of stigma attached to depressive symptoms that can lead to disclosure reluctance [30]. Clinically relevant depression not reaching diagnostic thresholds has been linked to depressive psychopathology in old age [31]. Depressive symptoms in older age can also arise out of a sense of inadequacy. In situations of loss, inadequacy stems from the feeling that one should be better able to cope with functional loss later in life [32]. Our participants average physical functioning score approximated the average expected score [21]. Nonetheless participants who were supported by family and/or a partner were prone to attributing physical functioning to a more variable state of health, not age. The enhancing effect of this identity process on depressive symptoms could be rooted in feelings of inadequacy. Depressive symptoms did, in turn, have a moderate negative effect upon participants' perceptions of age-related physical prowess, i.e. physical changes of aging. Norwegian older adults value the sense of control or believing and expecting that one's actions can affect what is going on in one's world [33]. Perhaps participants living with support expected more of themselves in terms of managing everyday activities?

We didn't focus on gender in this study but women did exhibit more positivity toward psychosocial loss. Perhaps the older Norwegian women taking part in this study were more socially connected than their male counterparts. Community participation is important in Norwegian society [16]. This cultural value has manifested among older Norwegian women and men living alone but taking part in meaningful social activities as less pessimism about loss [34]. Participants without post-secondary education equated aging with greater psychological growth. Although gender did not directly affect psychological growth, being a woman was significantly associated with having no post-secondary education. Lower education has solely explained the limited sense of control with age among Norwegian women [35]. We did not have a measure of perceived control in our secondary dataset. However a limited sense of control among our female participants may have evoked less expectation for growth opportunities compared to their male counterparts. The growth domain of the AAQ does have items pertaining to being better able to cope, believing that one's life has made a difference, and felt wisdom

\section{Limitations}

Ours is the first study to shed some light on identity process use among older Norwegian men and women. Nonetheless cross-sectional data yields findings of association, not causation. We did not know whether participants had depressive symptoms before those data were collected. Such histories could partly explain the moderate effect of depressive symptoms on psychosocial loss and physical change. We also used secondary data. Variables were combined to represent conceptual variables. We had few unusually frail participants for comparison, and no measures of formal support service use or perceived control. In future we will collect primary data over time, and recruit similar numbers managing at home with formal support services and living in nursing homes. Measuring perceived control and linking it with education can help us explain more variation in psychological growth. Describing the prevalence of depression in Norway and its assessment as not unusual for all older people may also reduce felt stigma for older Norwegians self-reporting depressive symptoms. Studying older people in different countries is no less essential. Identity accommodation has been linked with depressive symptoms among older Americans [13]. This Norwegian study implicates the identity assimilation process.

\section{Conclusions}

The findings of this study empirically contradict the Identity Process Theory. On the one hand, the 359 participants in this study did use the assimilation process alone by attributing their physical functioning to a more variable state of health, not to their chronological age. On the other hand, use of the assimilation process enhanced participants' depressive symptoms and negativity toward aging in relation to psychosocial loss, physical change, and psychological growth. We attribute our findings to upholding and denying Norwegian cultural beliefs and 
values. There is also a growing emphasis upon maintaining a youthful body image, and being energetic and fit at all ages in Norwegian society [36]. This youth-conscious cultural turn may partly explain older Norwegian's growing emphasis on caring for themselves and staying active enough to do so even with physical health limitations [37]. Older Norwegians optimism about self-care has been linked with not receiving family help, remaining active, and not seeing oneself as helpless [38]. Norwegian men and women in their 80s speak of not dwelling upon activities that they can't manage on their own [39]. Older Norwegians living alone have also expressed a desire for "not leaning too heavily" upon close family [34]. Older Norwegians living alone who remain connected with close others also tend to view loss as a normal part of aging [34]. This may further explain why older Norwegians tend to be non-demanding and thus reluctant to access formal support services [17]. Family obligation norms in Norway are now weaker in comparison to countries further south and east of Europe [40]. Whether these cultural turns lead others to replicate or contradict the negative effects of the identity assimilation process reported in this study should evoke curiosity.

\section{Acknowledgements}

The authors would like to acknowledge the contributions of the WHOQOL-OLD Group in the design of the original study that led to the compilation of the data sets. We acknowledge the work of Liv Halvorsrud and Janice Robinson for data collection in Norway and Canada respectively. Funding for the original project was obtained from the European Commission $5^{\text {th }}$ Framework Competition, and Diakonova University College funding, Oslo. We are also grateful to our Advances in Aging Research referees for their thoughtful reviews.

\section{References}

[1] Organization for Economic Cooperation and Development (2013) Pensions at a Glance 2013: OECD and G20 Indicators. OECD, Paris. http://dx.doi.org/10.1787/pension_glance-2013-en

[2] Statistics Norway (2014) Population Projections. Key Figures. http://www.ssb.no/en/befolkning/statistikker/folkfram/aar/2014-06-17?fane=tabell\&sort=nummer\&tabell=181191

[3] Statistics Norway (2013) Statistical Yearbook of Norway 2013, Table 107: Percentage of the Population Aged 65 and over. Selected Countries. http://www.ssb.no/en/sok?sok=percentage+of+population+over+65

[4] Daatland, S.O. (2007) Age Identifications. In: Fernandez-Ballestros, R., Ed., Geropsychology: European Perspectives for an Aging World, Hogrefe\& Huber, Cambridge, 31-48.

[5] Kalfoss, M., Low, G. and Molzahn, A. (2010) Reliability and Validity of the Attitudes to Ageing Questionnaire for Canadian and Norwegian Older Adults. Scandinavian Journal of Caring Sciences, 24, 75-85. http://dx.doi.org/10.1111/j.1471-6712.2010.00786.x

[6] Low, G., Molzahn, A. and Kalfoss, M. (2014) Cultural Frames, Qualities of Life, and the Aging Self. Western Journal of Nursing Research, 36, 664-663. http://dx.doi.org/10.1177/0193945913507635

[7] Whitbourne, S.K., Sneed, J.R. and Skultety, K.M. (2002) Identity Processes in Adulthood: Theoretical and Methodological Challenges. Identity: An International Journal of Theory and Research, 2, 29-45. http://dx.doi.org/10.1207/S1532706XID0201 03

[8] Whitbourne, S.K. and Collins, K.J. (1998) Identity Processes and Perceptions of Physical Functioning in Adults: Theoretical and Clinical Implications. Psychotherapy, 35, 519-530. http://dx.doi.org/10.1037/h0087666

[9] Skultety, K.M. and Whitbourne, S.K. (2008) Gender Differences in Identity Processes and Self-Esteem in Middle and Later Adulthood. Journal of Women \& Aging, 16, 175-188.

[10] Sneed, J.R. and Whitbourne, S.K. (2001) Identity Processing Styles and the Need for Self-Esteem in Middle-Aged and Older Adults. International Journal of Aging \& Human Development, 53, 311-321.

[11] Sneed, J.R. and Whitbourne, S.K. (2003) Identity Processing and Self-Consciousness in Middle and Later Adulthood. Journals of Gerontology: Psychological Sciences, 58, 313-319. http://dx.doi.org/10.1093/geronb/58.6.P313

[12] Langballe, E.M. and Evensen, M. (2011) Eldrei Norge: Forekomstavpsykiskeplageroglidelser (Older Adults in Norway: Prevalence of Mental Problems and Disorders). Folkehelseinstituttet, Oslo.

[13] Weinberger, M.I. and Whitbourne, S.K. (2010) Depressive Symptoms, Self-Reported Physical Functioning, and Identity in Community-Dwelling Older Adults. Ageing International, 35, 276-285. http://dx.doi.org/10.1007/s12126-010-9053-4

[14] Westerhof, G.J., Whitbourne, S.K. and Freeman, G.P. (2012) The Aging Self in a Cultural Context: The Relation of Conceptions of Aging to Identity Processes and Self-Esteem in the United States and the Netherlands. Journals of 
Gerontology, Psychological \& Social Sciences, 67, 52-60. http://dx.doi.org/10.1093/geronb/gbr075

[15] Warner-Søderholm, G. (2012) But We're All Vikings! Intercultural Identity within a Nordic Context. Journal of Intercultural Communication, 29, 1-14. http://www.immi.se/intercultural

[16] Gullestad, M. (1991) The Scandinavian Version of Egalitarian Individualism. Ethnologia Scandinavica, 21, 3-17.

[17] Robbins, J. (2012) A Blessing and a Curse? Political Institutions in the Growth and Decay of Generalized Trust: A Cross-National Panel Analysis, 1980-2009. PLOS ONE, 7, e35120. http://dx.doi.org/10.1371/journal.pone.0035120

[18] Meld. St. nr. 19. (2015) Public Health Report—Coping and Opportunities (Folkehelsemeldingen—Mestringogmuligheter) (2014-2015). Norwegian Government (Regjeringen).

https://www.regjeringen.no/no/dokumenter/meld.-st.-19-2014-2015/id2402807/?ch=1\&q

[19] Power, M., Quinn, K. and Schmidt, S., WHOQOL-OLD Group (2005) Development of the WHOQOL-OLD Module. Quality of Life Research, 14, 2197-2214. http://dx.doi.org/10.1002/gps.1683

[20] Laidlaw, K., Power, M.J. and Schmidt, S., the WHOQOL-OLD Group (2007) The Attitudes to Ageing Questionnaire (AAQ): Development and Psychometric Properties. International Journal of Geriatric Psychiatry, 22, 367-379. http://dx.doi.org/10.1002/gps.1683

[21] Ware, J., Kosinski, M., Turner-Bowker, D.T. and Gandek, B. (2002) User’s Manual for the SF-12v2 ${ }^{\circledR}$ Health Survey with a Supplemental Documenting SF-12v2 ${ }^{\circledR}$ Health Survey. QualityMetric Incorporated, Lincoln, Rhode Island.

[22] D’Ath, P., Katona, P., Mullan, E., Evans, S. and Katona, C. (1994) Screening, Detection and Management of Depression in Elderly Primary Care Attenders. The Acceptability and Performance of the 15 Item Geriatric Depression Scale (GDS15) and the Development of Short Versions. Family Practice, 11, 260-266. http://dx.doi.org/10.1093/fampra/11.3.260

[23] Hauge, S. and Kirkevold, M. (2010) Older Norwegians' Understanding of Loneliness. International Journal of Qualitative Studies on Health and Well-Being, 5. http://dx.doi.org/10.3402/qhw.v5i1.4654

[24] Slagsvold, B., Veenstra, M., Daatland, S.O., Hagestad, G., Hansen, T., Herlofson, K., Koløen, K. and Solem, P.E. (2012) Life-Course, Ageing, and Generations in Norway: The NorLAG Study. Norsk Epidemiologi, 22, 95-102. http://www.ntnu.no/ojs/index.php/norepid/article/view/1554/1448

[25] Taylor, A. (2002-2011) Using the GLM Procedure in SPSS. www.psy.mq.edu.au/psystat/documents/GLMSPSS

[26] Byrne, B.M., Ed. (2010) Structural Equation Modeling with AMOS: Basic Concepts, Applications, and Programming. 2nd Edition, Routledge, New York.

[27] Sedikides, C., Gaertner, L. and Toguchi, Y. (2003) Pancultural Self-Enhancement. Journal of Personality and Social Psychology, 84, 60-79. http://dx.doi.org/10.1037/0022-3514.84.1.60

[28] Daatland, S.O. and Lowenstein, A. (2005) Intergenerational Solidarity and the Family-Welfare State Balance. European Journal of Ageing, 2, 174-182. http://dx.doi.org/10.1007/s10433-005-0001-1

[29] Thoresen, K. and Solem, P.E. (2005) Will Loneliness Increase in the Years to Come? In: Slagsvold, B. and Solem, P.E., Eds., Tomorrow's Elderly, Norwegian Social Research, Oslo, 125-130.

[30] Kvaal, K. (2009) Depresjon hos eldre (Depression among Older Adults). Geraitrisk Sykepleie (Geriatric Nursing), 1, 4-5.

[31] Ridel-Heller, S.G., Busse, A. and Angermeyer, M.C. (2006) The State of Mental Health in Old Age across “Old” European Union-A Systematic Review. Acta Psychiatra Scandinavia, 113, 388-401. http://dx.doi.org/10.1111/j.1600-0447.2005.00632.x

[32] Clark, D.A., Beck, A.T. and Alford, B.A. (1999) Scientific Foundations of Cognitive Theory and Therapy of Depression. John Wiley, New York.

[33] Slagsvold, B. and Sørensen, A. (2013) Changes in Sense of Control in the Second Half of Life: Results from a 5-Year Panel Study. International Journal of Aging \& Human Development, 77, 289-308. http://dx.doi.org/10.2190/AG.77.4.b

[34] Kirkevold, M., Moyle, W., Wilkinson, C., Meyer, C. and Hauge, S. (2012) Facing the Challenge of Adapting to Life "Alone” in Old Age: The Influence of Losses. Journal of Advanced Nursing, 69, 393-403.

[35] Slagsvold, B. and Sørensen, A. (2008) Age, Education and the Gender Gap in the Sense of Control. International Journal of Aging \& Human Development, 6, 25-42. http://dx.doi.org/10.2190/AG.67.1.b

[36] Loland, N.W. (2000) The Aging Body: Attitudes toward Bodily Appearance among Physically Active and Inactive Women and Men of Different Ages. Journal of Aging and Physical Activity, 8, 197-213. http://journals.humankinetics.com/AcuCustom/Sitename/Documents/DocumentItem/1542.pdf

[37] Sundsli, K., Espnes, G.A. and Soderhamn, O. (2013) Being Old and Living Alone in Urban Areas: The Meaning of Self-Care and Health on the Perception of Life Situation and Identity. Psychology Research and Behavior Management, 6, 21-27. http://dx.doi.org/10.2147/PRBM.S46329 
[38] Dale, B., Soderhamn, U. and Soderhamn, O. (2012) Self-Care Ability among Home-Dwelling Older People in Rural Areas in Southern Norway. Scandinavian Journal of Caring Sciences, 26, 113-122. http://dx.doi.org/10.1111/j.1471-6712.2011.00917.x

[39] Birkeland, A. and Natvig, G.K. (2009) Coping with Ageing and Failing Health: A Qualitative Study among Elderly Living Alone. International Journal of Nursing Practice, 15, 257-264. http://dx.doi.org/10.1111/j.1440-172X.2009.01754.x

[40] Daatland, S.O., Herlofson, K. and Lima, I.A. (2011) Balancing Generations: On the Strength and Character of Family Norms in the West and East of Europe. Ageing \& Society, 31, 1159-1179.

http://dx.doi.org/10.1017/S0144686X10001315 